\title{
Correction to: Collaboration Makes Us Better: Time to Increase Equity in the Science of Hospice and Palliative Care by Candrian C, Furuno JP, Kavalieratos D, and Harrison KL. J Palliat Med 2019;22(12):1492. (DOI: 10.1089/jpm.2019.0348)
}

After publication of the article entitled, "Collaboration Makes Us Better: Time to Increase Equity in the Science of Hospice and Palliative Care," by Candrian C et al, J Palliat Med 22 p.1492 the authors reported an inadvertent omission of the palliative care organization Palliative Care Research Cooperative from the following sentences on page 1492:

"However, there is still no national conference or professional organization focused on the science of palliative care and where nonphysician scientists are eligible for senior leadership positions and awards. Nor is there an organization that reflects the interdisciplinary landscape of palliative care and provides a unifying home that transcends discipline."

The corrected text as it should have appeared is noted below:

"However, there is still no national conference or professional organization focused on the science of palliative care and where nonphysician scientists are adequately represented in senior leadership positions or equally eligible for awards. Only the Palliative Care Research Cooperative and National Palliative Care Research Center reflect the interdisciplinary landscape of palliative care and provides a unifying home that transcends discipline."

The online version of this article has been corrected.

The authors apologize for this error. 